\title{
Tuftsin-Bearing Liposomes Co-Encapsulated with Doxorubicin and Curcumin Efficiently Inhibit EAC Tumor Growth in Mice
}

This article was published in the following Dove Press journal: International Journal of Nanomedicine

\author{
Kalaimathi Murugesan' \\ Padmapriya Srinivasan ${ }^{1, *}$ \\ Raghunandan Mahadeva (D) ${ }^{1, *}$ \\ Chhitar M Gupta' \\ Wahajul Haq $\mathbb{D}^{2}$
}

'Institute of Bioinformatics and Applied Biotechnology (IBAB), Bangalore, India;

${ }^{2}$ Central Drug Research Institute (CDRI),

Medicinal and Process Chemistry

Division, Lucknow, India

*These authors contributed equally to this work
Correspondence: Kalaimathi Murugesan Institute of Bioinformatics and Applied Biotechnology (IBAB), Biotech Park, Electronic City Phase I, Bangalore 560I00, India

Tel +919585986415

Email mathi.biotech@gmail.com
Background: Targeted multidrug-loaded delivery systems have emerged as an advanced strategy for cancer treatment. In this context, antibodies, hormones, and small peptides have been coupled to the surface of drug carriers, such as liposomes, polymeric and metallic nanoparticles loaded with drugs, as tumor-specific ligands. In the present study, we have grafted a natural macrophage stimulating peptide, tuftsin, on the surface of the liposomes (LPs) that were loaded with doxorubicin (DOX) and/or curcumin (CUR), by attaching to its C-terminus a palmitoyl residue (Thr-Lys-Pro-Arg-CO-NH- $\left(\mathrm{CH}_{2}\right)_{2}-\mathrm{NH}-\mathrm{COC}_{15} \mathrm{H}_{31}$, P.Tuft) to enable its grafting within the liposome's bilayer.

Methods: The prepared drug-loaded liposomes (DOX LPs, CUR LPs, DOX-CUR LPs, P. Tuft-LPs, P.Tuft-DOX LPs, P.Tuft-CUR LPs, P.Tuft-DOX-CUR LPs) were thoroughly characterised in terms of particle size, drug content, encapsulation efficiency and structural properties using UV-visible spectroscopy, dynamic light scattering (DLS) and Fourier transform infrared spectroscopy (FTIR). The anti-cancer activity and drug toxicity of the liposomal formulations were examined on Ehrlich ascites carcinoma (EAC) tumor-induced mice model.

Results: A significant reduction in the tumor weight and volume was observed upon treating the tumor-bearing mice with palmitoyl tuftsin-grafted dual drug-loaded liposomes (P.TuftDOX-CUR LPs), as compared to the single drug/peptide-loaded formulation (DOX LPs, CUR LPs, DOX-CUR LPs, P.Tuft- LPs, P.Tuft-DOX LPs, P.Tuft-CUR LPs). Western blot analysis revealed that the tumor inhibition was associated with p53-mediated apoptotic pathway. Further, the biochemical and histological analysis revealed that the various liposomal preparation used in this study were non-toxic to the animals at the specified dose $(10 \mathrm{mg} /$ $\mathrm{kg})$.

Conclusion: In conclusion, we have developed a targeted liposomal formulation of P. Tuftsin-bearing liposomes co-encapsulated with effective anti-cancer drugs such as doxorubicin and curcumin. In experimental animals, tumor inhibition by P.Tuft-DOX-CUR LPs indicates the synergistic therapeutic effect of the peptide and the dual drug.

Keywords: palmitoyl-tuftsin, antitumor, doxorubicin, curcumin

\section{Introduction}

In recent years, combination drug therapy and multidrug-loaded delivery systems have emerged as an advanced approach to cancer treatment. ${ }^{1}$ Besides, combination of chemotherapeutic drugs along with the targeted peptide-based nanoformulations has shown great potential in cancer treatment. ${ }^{2}$ For instance, treatment with RGDKpeptide (arginine-glycine-aspartate)-bearing liposomes loaded with curcumin and 
doxorubicin have shown to exhibit a better effect on the tumor vasculature. ${ }^{3}$ Further, Sengupta et $\mathrm{al}^{4}$ developed an effective delivery system called "nanocell" for sequential release of multi-drugs within solid tumors. This means that an ideal drug delivery system must have a target-specific component and an effective release strategy at the specific site. Keeping this in view, we have employed in this study the target peptide, tuftsin-bearing liposomes, coencapsulated with hydrophobic (CUR) and hydrophilic (DOX) drugs.

Tuftsin is an immunomodulatory tetrapeptide (Thr-LysPro-Arg) derived from immunoglobulin IgG. ${ }^{5}$ Modification of tuftsin at the C-terminus with the addition of a fatty acyl chain (Thr-Lys-Pro-Arg-CO-NH- $\left(\mathrm{CH}_{2}\right)_{2}-\mathrm{NH}-\mathrm{COC}_{15} \mathrm{H}_{31}$; palmitoyl Tuftsin; P.Tuft) has been shown to facilitate easy grafting of this peptide on to the surface of the liposomes. ${ }^{6}$ It has been demonstrated that palmitoyl Tuftsin-bearing liposomes specifically bind to polymorphonuclear (PMN) cells, macrophages and monocytes and consequently induce the natural killer activity of these cells against tumors and pathogens. ${ }^{7}$ Furthermore, tuftsinbearing liposomised etoposide have shown to significantly inhibit the growth of fibrocarcinoma ${ }^{8}$ and administration of antigenic polypeptide along with tuftsin effectively inhibited the tumor growth in colorectal cancer. ${ }^{9}$ Despite the use of tuftsin for over forty years, the pathway through which tuftsin signals have not been fully elucidated, lately it was identified that tuftsin signals by binding to neuropilin-1 receptor which plays an important role in blood vessel formation and microvascular permeability of tumor cells. ${ }^{10,11}$ In this study, we have used palmitoyl tuftsin to enable its efficient grafting on to the liposome surface, and also to further complement the anti-tumorigenic potential of the drugs encapsulated in the liposomes.

Doxorubicin (DOX) is an antitumor antibiotic widely used to treat several types of cancers. ${ }^{12}$ However, its clinical use is restricted vowing to its drug resistance and side effects. ${ }^{13}$ Therefore, various attempts have been made to find new chemosensitizers, to improve the efficacy of doxorubicin against multi drug-resistant (MDR) cancer cells. ${ }^{14}$ Curcumin is one such compound that acts as a chemosensitizer to reverse doxorubicin resistance against solid tumors by down regulation of NF-kB transcription factor. ${ }^{15}$ In addition to its strong anti-cancer activity, curcumin is now being explored for its unique ability to enhance the effects of chemotherapeutics when administered along with several anticancer drugs, such as doxorubicin, cisplatin, etc. ${ }^{16}$ For instance, treatment with poly (butyl

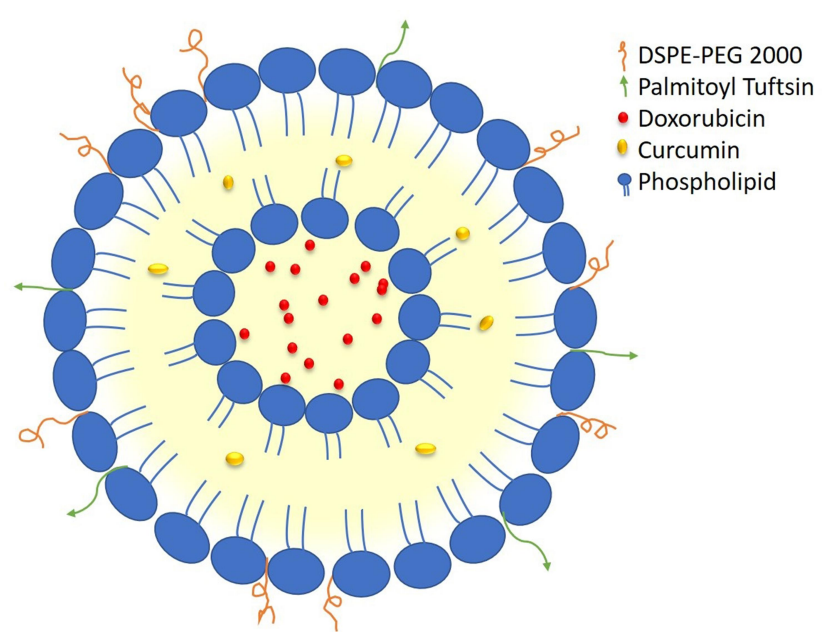

Figure I The schematic representation of the assembly of tuftsin-bearing liposomes encapsulated with DOX and CUR.

Abbreviations: DSPE-PEG, distearoyl-L-A-phosphatidylethanolamine; DOX, doxorubicin; CUR, curcumin; LPs, liposomes.

cyanoacrylate) nanoparticles (PBCA-NPs) loaded with DOX and CUR efficiently reversed MDR resistance in $\mathrm{MCF}-7$ breast cancer cell line. ${ }^{17} \mathrm{We}$, therefore, considered it appropriate to co-encapsulate curcumin with doxorubicin as a chemosensitizer in tuftsin-bearing liposomes ${ }^{18}$ to enhance the efficacy of doxorubicin against EAC induced solid tumors. Figure 1 is a schematic representation of the tuftsin-bearing liposomes encapsulated with the dual drug.

\section{Materials and Methods Preparation of Liposomes}

Palmitoyl Tuftsin (P.Tuft) was prepared as reported earlier. ${ }^{19}$ The solvent evaporation method was used for the preparation of various liposomal formulations (LPs) used in this study. ${ }^{20}$ Briefly, in $10 \mathrm{~mL}$ of chloroform, curcumin (CUR; 3mg), cholesterol (15mg), DSPE-PEG $2000(12.5 \mathrm{mg})$ and egg lecithin (120mg) were dissolved. In a rotary evaporator, the mixture was evaporated at $45^{\circ}$ $\mathrm{C}$, and the thin layer formed was dried overnight for complete removal of the solvent. The thin film was then suspended in phosphate-buffered saline (PBS) containing $50 \mathrm{mg}$ of P.Tuft for $30 \mathrm{mins}$. The mixture was then sonicated at $500 \mathrm{~W}$ for 2 min using probe-type ultrasonicator. Curcumin-loaded liposomes (CUR-LPs) with and without P.Tuft was prepared using the same method. The unencapsulated curcumin was removed by centrifugation at $5000 \mathrm{rpm}$ for $45 \mathrm{~min}$. Doxorubicin (DOX) loaded liposomes were prepared by preheating the liposomes at $37^{\circ} \mathrm{C}$ in a water bath. Followed by the addition of $5 \mathrm{mg} /$ 
$\mathrm{mL}$ of DOX to the preheated liposomes with gentle stirring for $15 \mathrm{~min}$ at $37^{\circ} \mathrm{C}$.

\section{Characterisation of Liposomes}

The particle size distribution of the liposomes was analysed using DLS (Malvern zetasizer nano ZS90, Malvern, UK) with the following parameters; refractive index 1.59, scattering angle of $90^{\circ}$ and viscosity of 0.89 . FT-IR analysis was carried out as described by Murugesan et al. ${ }^{21}$ Amounts of curcumin entrapped inside the liposomes was determined by measuring absorption at $450 \mathrm{~nm}$ after lysis of the liposomes with $1 \%$ triton-X. The amount of encapsulated DOX in the liposomes was determined by measuring absorption at $483 \mathrm{~nm}$ using UV-visible spectrophotometer X (Tecan Infinite M 200 pro, Tecan Austria GmbH, Austria) after lysis of liposomes with $10 \%$ SDS (w/v). P.Tuftsin was quantified by using HPLC with fluorescence detector. Briefly, the synthesised P.Tuftsin-bearing liposomes were dissolved in methanol and then diluted with a mixture of acetonitrile and water $(20: 80, \mathrm{v} / \mathrm{v}), 2 \mathrm{ul}$ of the resultant solution was then injected into the HPLC system (Agilent 1100 series). C18 column was used for chromatographic separation, the mobile phase consisted of acetonitrile and $0.2 \%$ formic acid with a flow rate of $1 \mathrm{~mL} / \mathrm{min}$.

Entrapment efficiency $(\mathrm{EE} \%)=\frac{\text { Concentration of entrapped drug }}{\text { Total drug concentration }} \times 100$

\section{In vitro Release Studies}

The liposomal formulations (CUR LPs, DOX LPs, P.Tuft LPs, P.Tuft-CUR LPs, P.Tuft-DOX LPs, P.Tuft-DOX-CUR LPs) equivalent to $1 \mathrm{~mL}$ were filled in the dialysis bag with a cut off of 12-14KDa. Each dialysis bag was immersed in a solution containing $0.01 \mathrm{M}$ PBS ( $\mathrm{pH} 7.4$ ) with $1 \%$ tween 80 and $20 \%$ ethanol placed on a shaker at $100 \mathrm{rpm}$. One milliliter of the sample was then withdrawn at $1 \mathrm{hr}, 2 \mathrm{hr}, 4$ $\mathrm{hr}, 8 \mathrm{hr}, 12 \mathrm{hr}, 24 \mathrm{hr}, 36 \mathrm{hr}$ and $48 \mathrm{hr}$ and replaced with $1 \mathrm{~mL}$ of PBS. The amount of DOX and CUR released at each time point was then analysed. The experiment was carried out in triplicate.

\section{Preparation of Rhodamine B-Labelled Liposomes}

Rhodamine B isothiocyanate $(5 \mathrm{mg})$ was solubilised in $1 \mathrm{~mL}$ of DMSO. From this solution, $200 \mu \mathrm{L}$ was added to $1 \mathrm{~mL}$ of various preparations of liposomes (Blank LPs, CUR LPs, DOX LPs, P.Tuft LPs, P.Tuft-CUR LPs, P.TuftDOX LPs, P.Tuft-DOX-CUR LPs) followed by addition of
$1 \mathrm{~mL}$ of $2 \mathrm{M} \mathrm{NaHCO}_{3}$ buffer. The mixture was then incubated in dark for $12 \mathrm{hr}$ at $4^{\circ} \mathrm{C}$. Free rhodamine $\mathrm{B}$ was removed by dialysis against distilled water.

\section{In vitro Cellular Uptake of Liposomes}

Human cervical cancer cell line (HeLa) was procured from NCCS (National Center for Cell Sciences), Pune, India. The cells were grown in $50 \mathrm{~mL}$ flask in MEM media and about $80 \%$ confluency the cells were detached by trypsinization, pelleted, and suspended in fresh media. $2 \mathrm{~mL}$ of $5 \times 10^{7}$ cells were coated on the coverslips and kept for $12 \mathrm{hr}$ to adhere. To it was added 200ul of rhodamine B-labelled preparations of various types of liposomes (Blank LPs, CUR LPs, DOX LPs, DOX-CUR LPs, P. Tuft LPs, P.Tuft-CUR LPs, P.Tuft-DOX LPs, P.TuftDOX-CUR LPs) and the mixture was incubated further for $12 \mathrm{hr}$. After incubation, the cells were fixed for 10 mins with $4 \%$ paraformaldehyde. The nuclei of the cell were stained with DAPI (4',6-diamidino-2-phenylindole), and the fluorescence images were captured and analysed by confocal laser-scanning microscope (FV1000, Tokyo, Japan).

\section{In vivo Efficacy in EAC Tumor-Induced Mice}

The animal study was approved by CPCSEA ("committee for the purpose of control and supervision of experiments on animals", Government of India, Animal welfare division, Reg. No. 1994/GO/ReBi/S/17/CPCSEA) and all the experiments were conducted according to the guidelines and regulation of CPCSEA. The in vivo efficacy of different types of liposomes was evaluated in Ehrlich ascites carcinoma (EAC) tumor-bearing mouse model. The tumor was induced in swiss albino mice by injection of $1 \times 10^{6}$ EAC cells on either of the hind limb of mice. When tumor volume reached $\simeq 200 \mathrm{~mm}^{3}$, the animals were segregated into eight experimental groups ( 5 animals per group). The formulations (Blank LPs, CUR LPs, DOX LPs, DOXCUR LPs, P.Tuft LPs, P.Tuft-CUR LPs, P.Tuft-DOX LPs, P.Tuft-DOX-CUR LPs and untreated control) were given intraperitoneally at a dose of $10 \mathrm{mg} / \mathrm{kg}$ every alternate day for 30 days. The tumor volume and body weight were monitored for 30 days. The tumor volume was calculated with a digital caliper using the formula $\mathrm{V}=(\mathrm{LxWxW}) / 2$, where $\mathrm{V}$ is tumor volume, $\mathrm{W}$ is tumor width, $\mathrm{L}$ is tumor length. 


\section{Western Blotting}

Protein samples were isolated from $100 \mathrm{mg}$ tumor tissues from each treatment groups (CUR LPs, DOX LPs, DOXCUR LPs, P.Tuft LPs, P.Tuft-CUR LPs, P.Tuft-DOX LPs, P.Tuft-DOX-CUR LPs and untreated control). The protein concentration was determined by Bradford method. The protein samples were then resolved on sodium dodecyl sulphate polyacrylamide gel electrophoresis (SDS-PAGE) . The resolved protein samples were blotted onto PVDF membrane using semi-dry transfer method (TransblotTurbo blotting system, Biorad, USA). The membranes were treated with $5 \%$ non-fat milk for 1 hour at room temperature. The membranes were then incubated with primary antibody (Bcl-2, BAX and p53) for 2 hours followed by incubation with streptavidin-horseradish peroxidase conjugate for 1 hour. The immunoblots were developed using chemiluminescence detection reagent (Clarity Western ECL blotting substrate, Biorad, USA). The intensity of the bands was captured using Syngene G: Box gel doc system and the bands were quantified using GelQuant.Net, BiochemLab solutions.

\section{Assessment of Drug Toxicity}

The drug toxicity was evaluated after treatment of the mice with various preparations of liposomes (Blank LPs, CUR LPs, DOX LPs, DOX-CUR LPs, P.Tuft LPs, P.Tuft-CUR LPs, P.Tuft-DOX LPs, P.Tuft-DOX-CUR LPs) for 30 days. At the end of the experiment, blood samples were collected from mice in each treatment groups and serum was separated. The drug toxicity assessment was made as per the protocol described in ALT/AST activity assay kit (Abcam, India).

\section{Histological Analysis}

\section{The $\mathrm{H}$}

\& E staining was performed as described by Murugesan et al. ${ }^{21}$ Briefly, the tumor tissues and the organs were fixed in formalin and then embedded in paraffin. The tissues were sectioned into $5 \mu \mathrm{m}$ thickness. The protocol followed dewaxing of the tissue slides with xylene for 5 mins followed by dehydration in ethanol gradient (100-30\%). The slides were then washed with distilled water and then incubated with hematoxylin for $5 \mathrm{~min}$. The slides were washed with $1 \%$ acid-alcohol and then counter stained with eosin for $1 \mathrm{~min}$. The tissue slides were dehydrated in ethanol gradient followed by incubation with xylene for 5 min. The slides were then fixed using DPX mounting medium and observed under the microscope.

\section{Statistical Analysis}

All experiments were performed in triplicates and reported as mean $\pm \mathrm{SD}$. One-way analysis of variance was used to determine the statistical significance of the drug release assay and tumor size. Significant change is considered at $p$-value $\leq 0.05$. The statistical data was evaluated on SPSS v20.0 software.

\section{Results}

\section{Particle Size and Entrapment Efficiencies}

The hydrodynamic diameters of the various formulations containing DOX LPs, CUR LPs, DOX-CUR LPs, P.Tuft LPs, P. Tuft-CUR LPs, P.Tuft-DOX LPs, P.Tuft-DOX-CUR LPs were measured by DLS (dynamic light scattering) and the size was within the range of 100-140nm (Figure 2, Table 1). The drug entrapment efficiencies of doxorubicin and curcumin loaded liposomes were determined spectrophotometrically (Figure 3). Curcumin entrapment efficiency in liposomes was found to be $(70-78 \%)$ and the entrapment efficiency of doxorubicin was about (96-98\%). The amount of Tuftsin in liposomes ranged from $50-60 \%$ of the total amount.

\section{FTIR Analysis}

The encapsulation of DOX/CUR in the liposomes was confirmed by FTIR spectroscopy. The FTIR absorption spectra (Figure 4) ranged from $3365 \mathrm{~cm}^{-1}$ to $713 \mathrm{~cm}^{-1}$. The characteristic peaks of curcumin were found at $3508 \mathrm{~cm}^{-1}$ represents the $-\mathrm{OH}$ stretching, peak at $1271 \mathrm{~cm}^{-1}$ represents $\mathrm{C}-\mathrm{O}$ stretching, and $1023 \mathrm{~cm}^{-1}$ represents $\mathrm{C}-\mathrm{O}-\mathrm{C}$ stretching. The main characteristic peaks of DOX corresponds to $-\mathrm{NH}_{2}$ stretching at $3450 \mathrm{~cm}^{-1}, \mathrm{C}-\mathrm{C}$ stretching corresponds to peak at $1410 \mathrm{~cm}^{-1}$, and $1073 \mathrm{~cm}^{-1}$ corresponds to $\mathrm{C}=\mathrm{O}$ stretching vibrations. The signature peaks of P.Tuft were found at $1300 \mathrm{~cm}^{-1}\left(-\mathrm{RNH}_{2}\right), 1747 \mathrm{~cm}^{-1}$ and $1033 \mathrm{~cm}^{-1}$ (C-C stretching). Once encapsulated with DOX or CUR the characteristic peaks were shifted from 1747 to 1781,1073 to 1082 and 1271 to $1267 \mathrm{~cm}^{-1}$, respectively. The occurrence of the characteristic peaks corresponding to DOX/CUR in each of the liposomes indicated that the drugs were successfully loaded in the liposomes.

\section{In vitro Release Kinetics}

A diphasic release pattern was observed for DOX and CUR, with an initial rapid release up to $4 \mathrm{~h}$ and sustained release until $48 \mathrm{~h}$ (Figure 5A and figure 5B). DOX release at $48 \mathrm{~h}$ was about $54-63 \%$ in DOX LPs, P.Tuft-DOX LPs and P.Tuft-DOX-CUR LPs. Similarly, in case of Cur about 

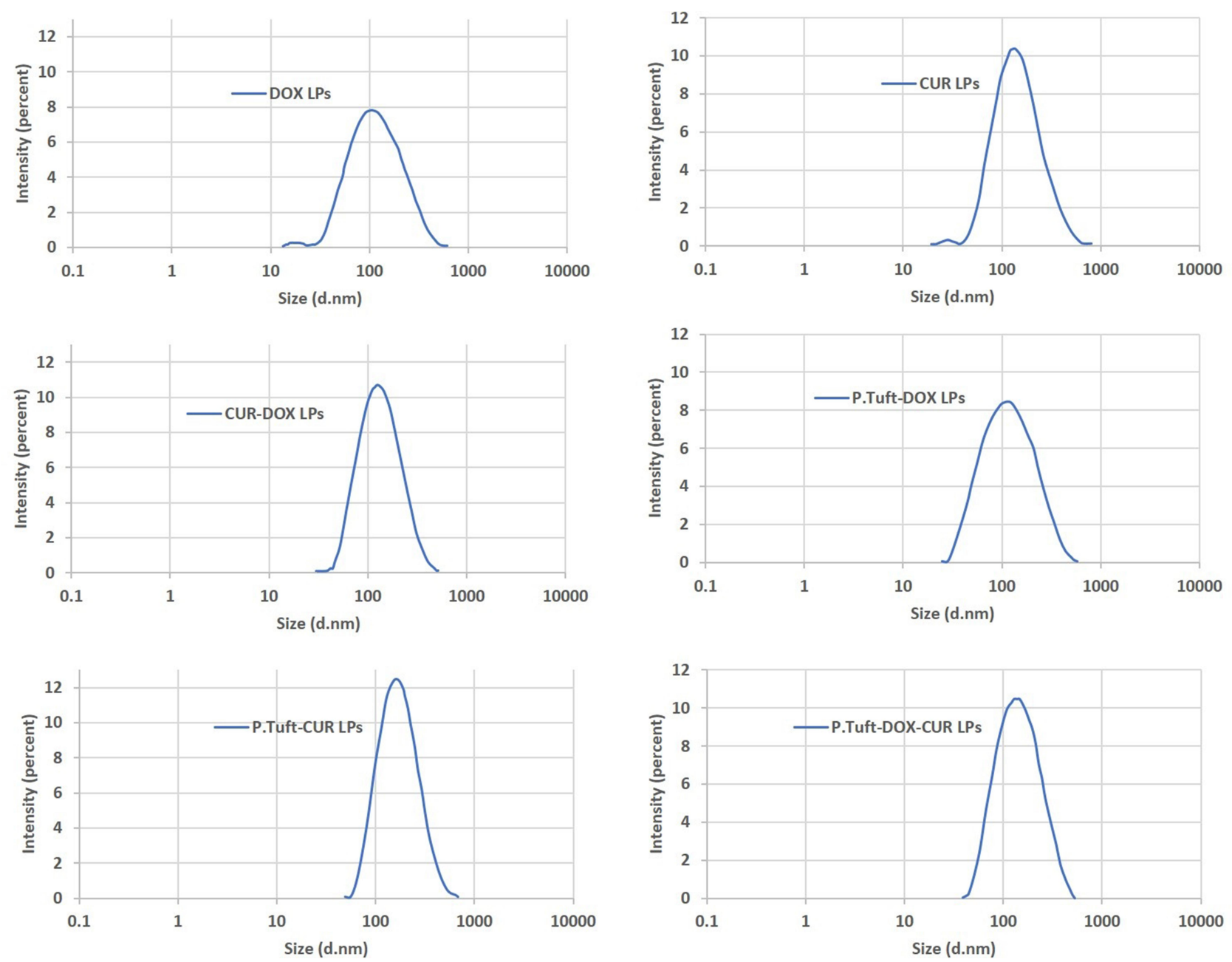

Figure 2 Size determination of LPs.

Notes: Particle size distribution of Liposomes including, DOX LPs, CUR LPs, CUR-DOX LPs, P.Tuft-CUR LPs, P.Tuft-DOX LPs, P.Tuft-DOX-CUR LPs as measured by DLS. Abbreviations: DLS, dynamic light scattering; P.Tuft, palmitoyl tuftsin; DOX, doxorubicin; CUR, curcumin.

46-55\% release was observed in CUR LPs, P.Tuft-CUR LPs and P.Tuft-DOX-CUR LPs. No significant difference was observed in release pattern of both DOX and CUR from P.Tuft-DOX LPs, P.Tuft-CUR LPs and P.Tuft-DOXCUR LPs when compared with DOX/CUR LPs. The results indicate that presence of P.Tuftsin on the surface of the liposomes does not alter the release pattern of the drugs from liposomes. However, a slight decrease in release of DOX and CUR on addition of P.Tuftsin may be due to high encapsulation efficacy of the drugs within

Table I The Size, Polydispersity Index and Entrapment Efficiency of Liposomes

\begin{tabular}{|c|c|c|c|c|c|}
\hline \multirow[t]{2}{*}{ Liposomes } & \multirow[t]{2}{*}{ Average Size (nm) } & \multirow[t]{2}{*}{ Polydispersity Index (PDI) } & \multicolumn{3}{|c|}{ Entrapment Efficiency (\%) } \\
\hline & & & CUR & DOX & Tuftsin \\
\hline DOX LPS & 116 & 0.49 & & $97.4 \pm 0.6$ & \\
\hline CUR LPs & 136 & 0.31 & $74.9 \pm 4.3$ & & \\
\hline DOX-CUR LPs & 132 & 0.27 & $73.2 \pm 1.5$ & $98.1 \pm 0.3$ & \\
\hline P.Tuft LPs & 125 & 0.35 & & & $53 \%$ \\
\hline P.Tuft-CUR LPs & 128 & 0.4 & $76.8 \pm 4.2$ & & $57.2 \%$ \\
\hline P.Tuft-DOX LPs & 111 & 0.35 & & $98.4 \pm 1.4$ & $56.9 \%$ \\
\hline P.Tuft-DOX-CUR LPs & 134 & 0.22 & $73.2 \pm 4.8$ & $96.5 \pm 2.8$ & $52.3 \%$ \\
\hline
\end{tabular}



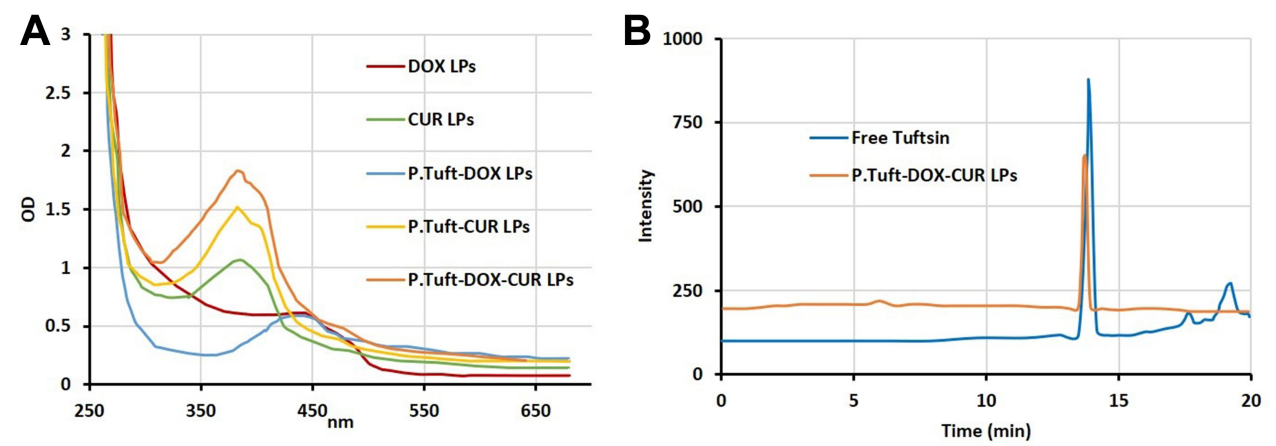

Figure 3 Characterisation of LPs.

Notes: UV-spectrophotometric detection and quantification of entrapped DOX and CUR in different kinds of LPs. (A) Quantification of tuftsin by RP-HPLC method, tuftsin fraction eluting at $13.9 \mathrm{~min}$ at $227 \mathrm{~nm}($ B).

Abbreviation: RP-HPLC, reverse phase liquid chromatography.

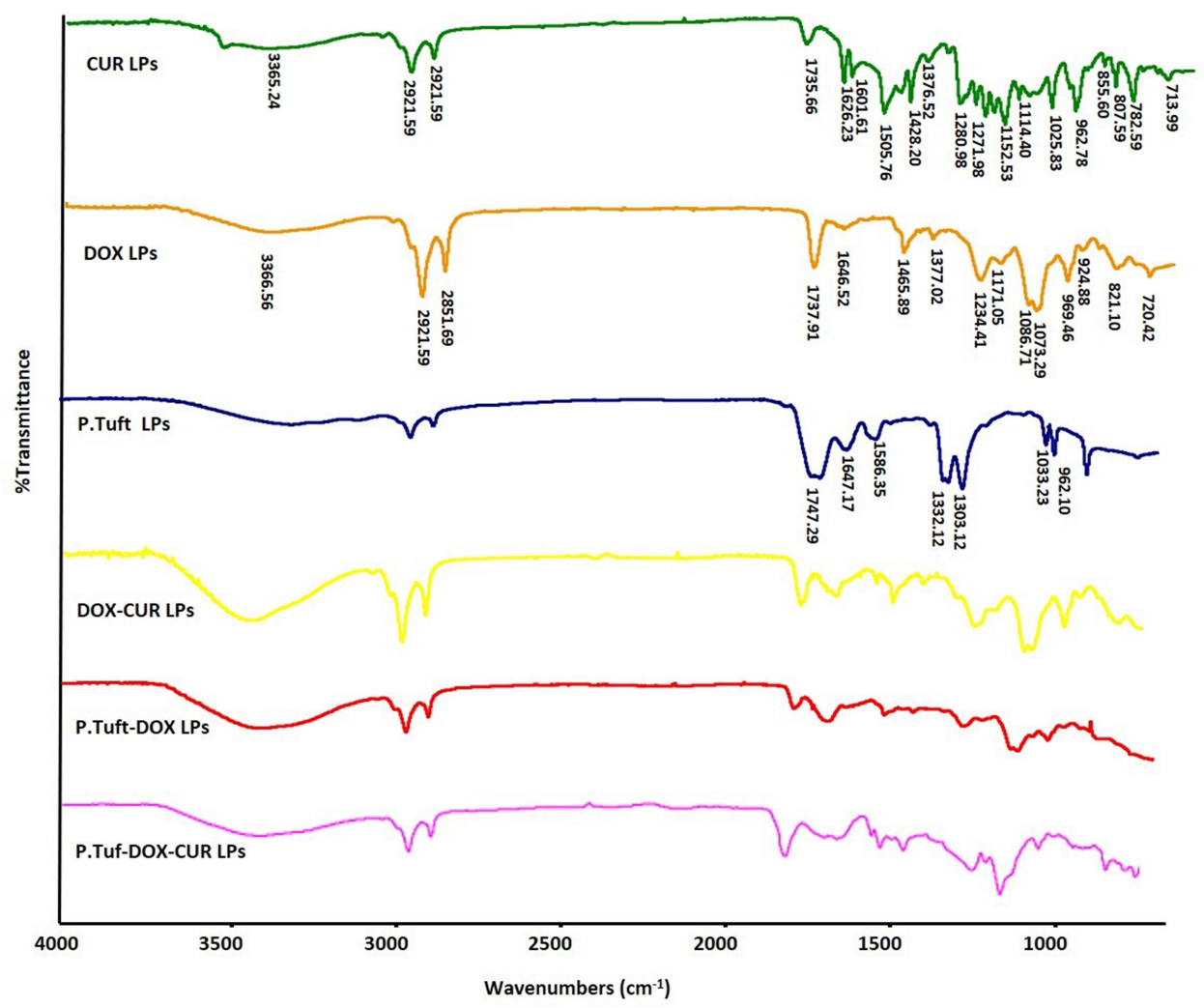

Figure 4 Characterization of structural properties by Fourier transform infrared spectroscopy (FTIR).

Note: FTIR analysis of different kinds of LPs including CUR LPs, DOX LPs, P.Tuft LPs, P.Tuft-DOX LPs, P.Tuft-DOX-CUR LPs.

the liposomes which attributed to slower burst release compared to DOX/CUR LPs.

\section{In vitro Cellular Internalisation of Liposomes}

The internalization of rhodamine B-labelled LPs in HeLa cells was visualised by confocal laser scanning microscopy. The red intensity indicated the level of internalization of rhodamine B-labelled LPs inside the cells. As shown in
Figure 6, all the liposomal formulations showed intracellular rhodamine B concentration after $12 \mathrm{hr}$. The red fluorescence intensity in the cytosol of the HeLa cells confirmed the uptake of Rhodamine-B labelled LPs by the cancer cells.

\section{In vivo Efficacy of Different Kinds of Liposomes}

The tumor-bearing mice were subjected to treatment with different liposomal formulations (Blank LPs, CUR LPs, 

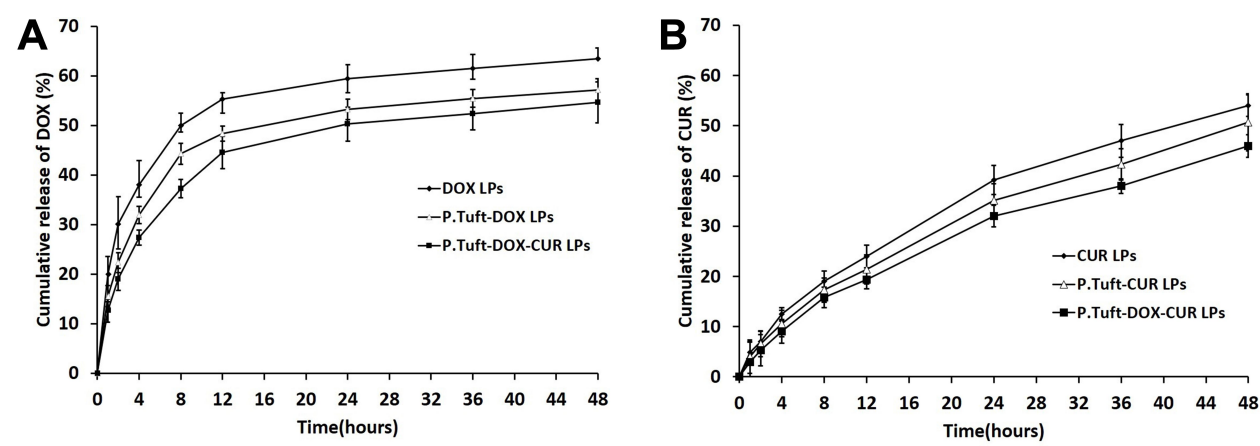

Figure 5 In vitro release profile of DOX and CUR.

Notes: Percent cumulative release of DOX (A); percent cumulative release of CUR (B). The experiment was carried out using dialysis membrane diffusion technique. The data are representative of three experiments. Each value represents mean $\pm S D$ of three experiments.
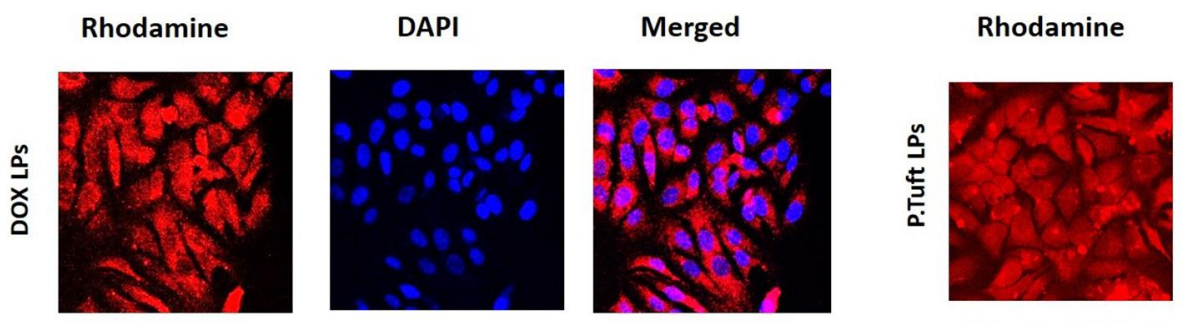

DAPI

Merged
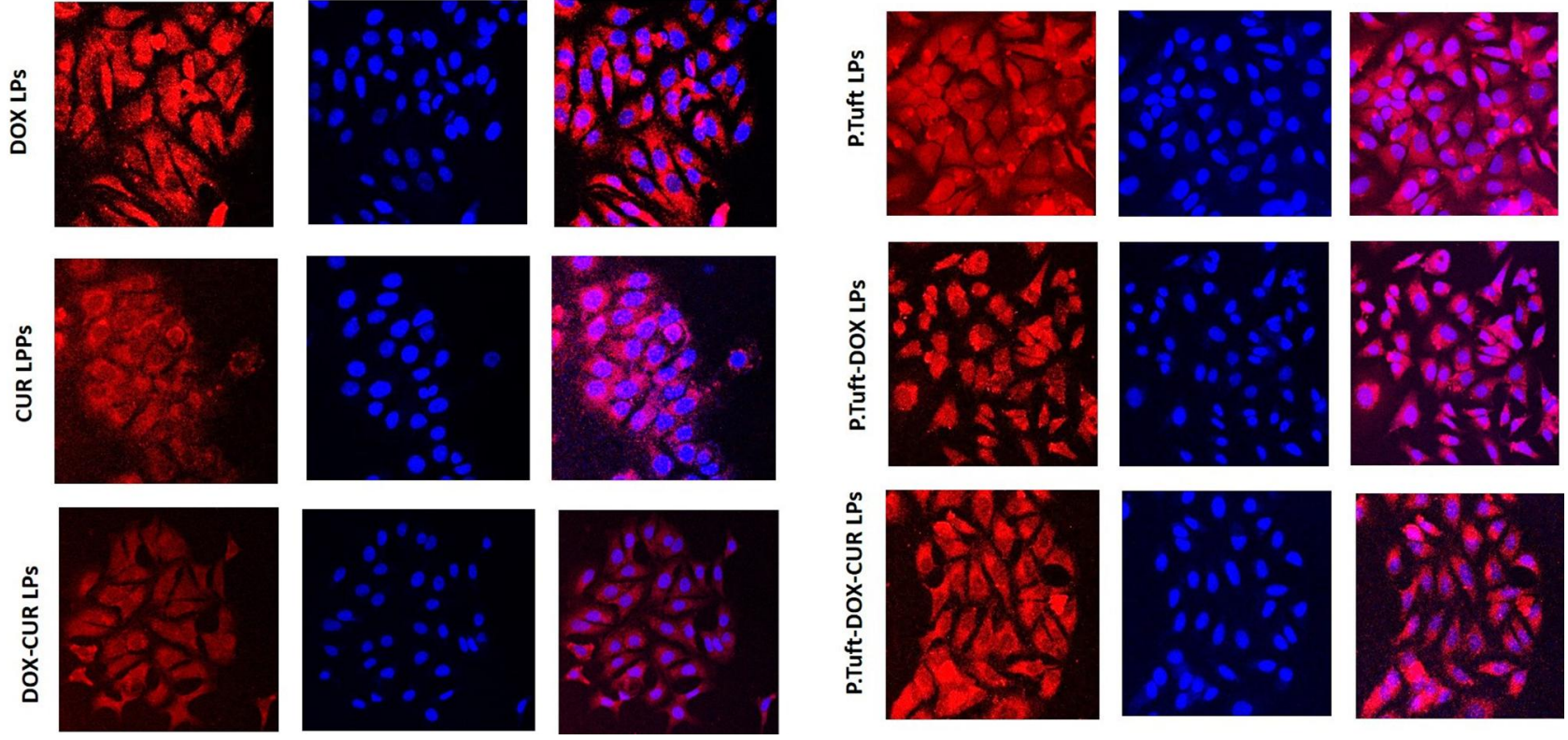

Figure 6 In vitro cellular uptake study.

Notes: Confocal images of HeLa cells after $12 \mathrm{~h}$ of incubation with different kinds of LPs at the same concentration $0.1 \mathrm{mg} / \mathrm{mL}$; the nuclei were stained by DAPI (blue), and all of the LPs are labeled by rhodamine B (red).

DOX LPs, DOX-CUR LPs, P.Tuft LPs, P.Tuft-CUR LPs, P. Tuft-DOX LPs, P.Tuft-DOX-CUR LPs and untreated control) for 15 doses at a dose of $10 \mathrm{mg} / \mathrm{kg}$. The tumor volume and body weight were measured every day for 30 days. The tumor volume in each group at the start of the experiment ranged from 0.2 to $0.26 \mathrm{~cm}^{3}$. At the end of treatment, the average tumor volume was $5.84 \mathrm{~cm}^{3}$ for control group, $6 \mathrm{~cm}^{3}$ for blank LPs, $3.64 \mathrm{~cm}^{3}$ for P.Tuft LPs, $3 \mathrm{~cm}^{3}$ for CUR LPs, $2.48 \mathrm{~cm}^{3}$ for DOX LPs, $1.84 \mathrm{~cm}^{3}$ for DOX-CUR LPs, $1.72 \mathrm{~cm}^{3}$ for P.Tuft-CUR LPs, $1.75 \mathrm{~cm}^{3}$ for P.Tuft-DOX LPs, $1.53 \mathrm{~cm}^{3}$ for P.Tuft-DOX-CUR LPs, respectively (Figure 7A). At the end of treatment, the average tumor volume of CUR LPs, DOX LPs, P.Tuft LPs $\left({ }^{*} \mathrm{P}<0.05\right)$ and
DOX-CUR LPs, P.Tuft-CUR LPs, P.Tuft-DOX LPs, P.TuftDOX-CUR LPs decreased significantly $\left({ }^{* *} \mathrm{P}<0.01\right)$ compared with the control groups (Figure 7B). The results indicate that P.Tuft co-encapsulated with CUR and DOX suppressed the tumor growth more efficiently, compared to the single drug or the dual drug formulations. The initial body weight of mice ranged from 30-31g (Figure 7C) and the weight changes towards the end of the experiments in all the groups were found to be similar. The average tumor weight after 30 days of treatment was $6.8 \mathrm{~g}$ for control, 6.2 $\mathrm{g}$ for blank, $4.9 \mathrm{~g}$ for P.Tuft LPs, $4.5 \mathrm{~g}$ for CUR LPs, $4 \mathrm{~g}$ for DOX LPs, $3.8 \mathrm{~g}$ for DOX-CUR LPs, $3.32 \mathrm{~g}$ for P.Tuft-DOX, $3.1 \mathrm{~g}$ for P.Tuft-CUR and $2 \mathrm{~g}$ for P.Tuft-DOX-CUR LPs, 


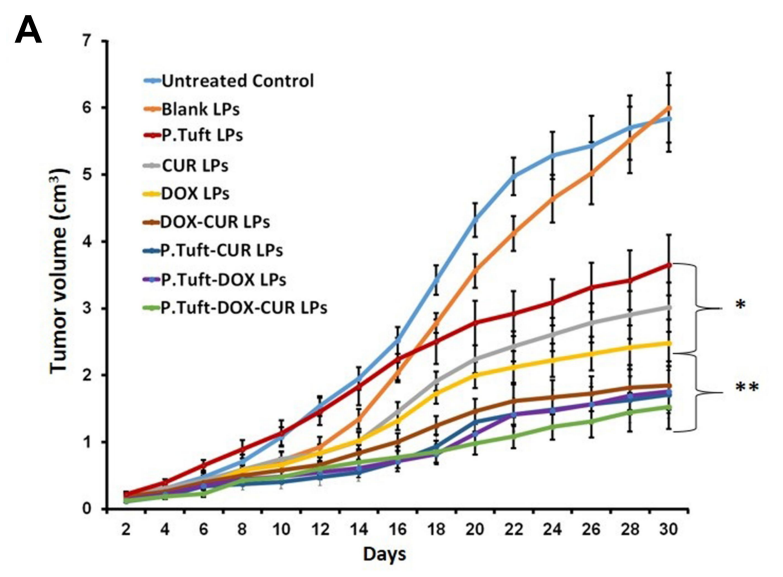

C

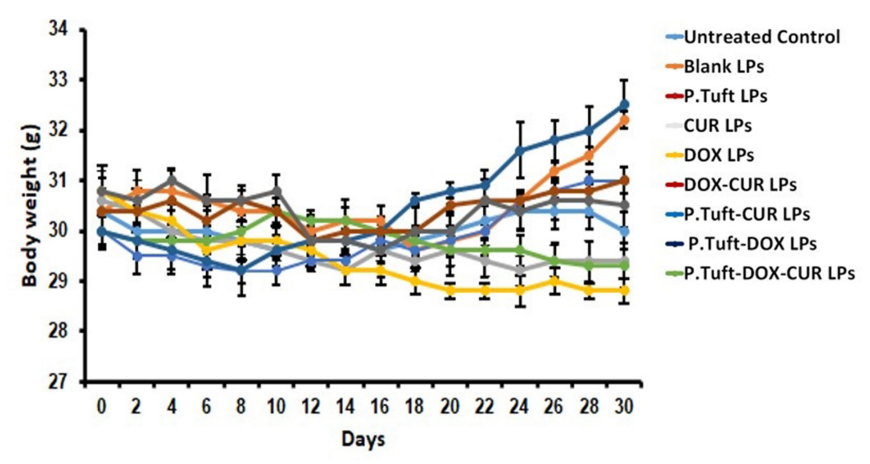

B

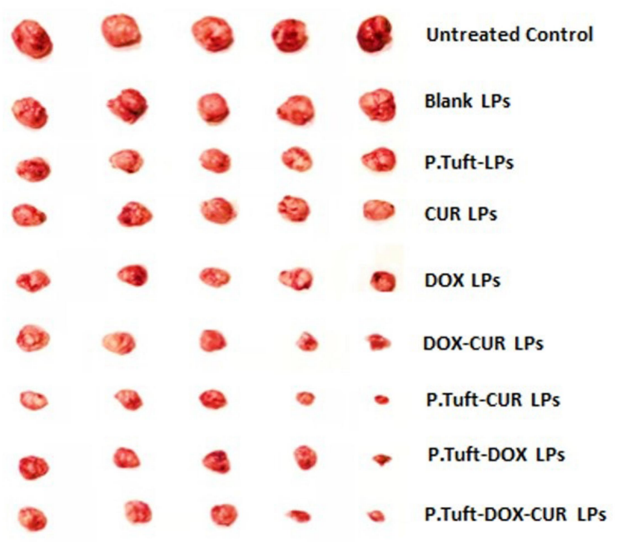

D

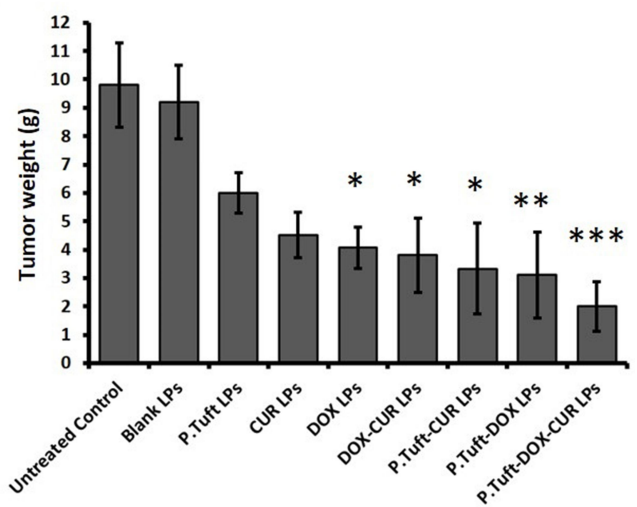

Figure 7 The in vivo effects different kinds of LPs in EAC tumor-bearing mice.

Notes: Growth curve of EAC tumors in each group (A) Images of tumors removed from mice in each group after treatment (B) Individual body weight of mice after treatment $(\mathbf{C})$ Individual tumor weight of mice after 30 days of treatment (D). Each value represents mean \pm SD from fifteen mice $* \mathrm{P}<0.05$, $* * \mathrm{P}<0.0 \mathrm{I}, * * * \mathrm{P}<0.00 \mathrm{I}$.

respectively (Figure 7D). The results indicate that all the formulations administered at a concentration of $10 \mathrm{mg} / \mathrm{kg}$ significantly reduced the tumor growth in mice, with insignificant changes in the body weight.

\section{Expression of Apoptotic Proteins}

The effect of various liposomal formulations on the expression of major apoptotic regulatory proteins (BCL-2, BAX, p53) was determined using Western blotting. As seen in Figure 8, liposomal formulations with P.Tuftsin (P.Tuft LPs, P.Tuft-DOX LPs, P.Tuft-DOXCUR LPs) significantly increased the regulation of BAX about $(2-2.5$ fold, $\mathrm{P}<0.01)$ and p53 about (2 fold, $\mathrm{P}<0.05$ ) when compared to untreated control. Whereas BCL-2 expression decreased by (0.3-0.5 fold, $\mathrm{P}<0.05)$ in $\mathrm{P}$.Tuftin treatment groups in relation to untreated control. The result indicates that the tumor suppression may be associated with p53-mediated apoptotic pathway .

\section{Assessment of Drug Toxicity}

At the end of 30 days of treatment with blank LPs, CUR LPs, DOX LPs, DOX-CUR LPs, P.Tuft LPs, P.Tuft-CUR LPs, P.Tuft-DOX LPs, P.Tuft-DOX-CUR LPs, blood samples were collected from all the treatment groups and the serum was separated. ALT/AST levels in the serum were analysed. The results indicated that the levels were within the normal range among all the treatment groups (Figure 10; ALT $<60 \mathrm{U} / \mathrm{L}, \mathrm{AST}<100 \mathrm{U} / \mathrm{L}$ ). However, DOX-LPs and P. Tuft-DOX LPS showed a mild elevation in ALT and AST levels.

\section{Histopathology}

The specimens of tumor tissues, kidney, liver and spleen were excised from the mice of experimental and control groups $(\mathrm{P}$. Tuft-CUR LPs, P.Tuft-DOX LPs, P.Tuft-DOX-CUR LPs). The $\mathrm{H}$ and $\mathrm{E}$ stained sections of tumor tissue and organs were observed for changes such as steatoses, infiltrative cells, necrosis, enlargement of organs (hyperplasia), 


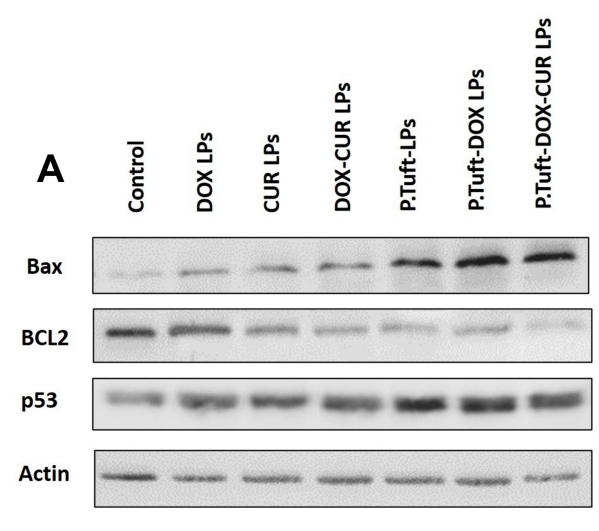

C

BCL2

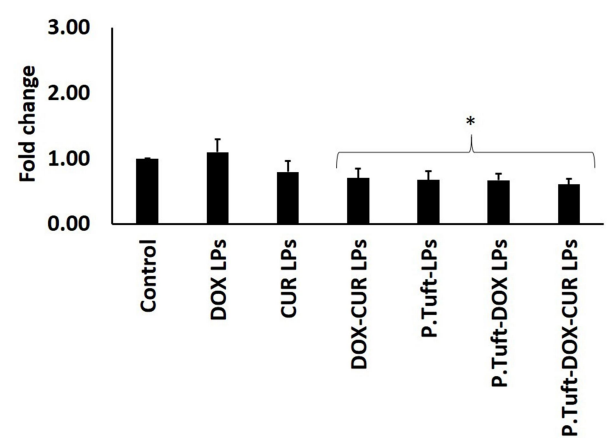

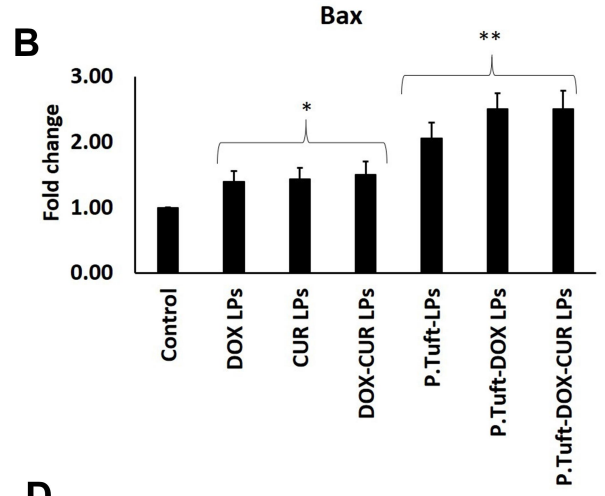

p53

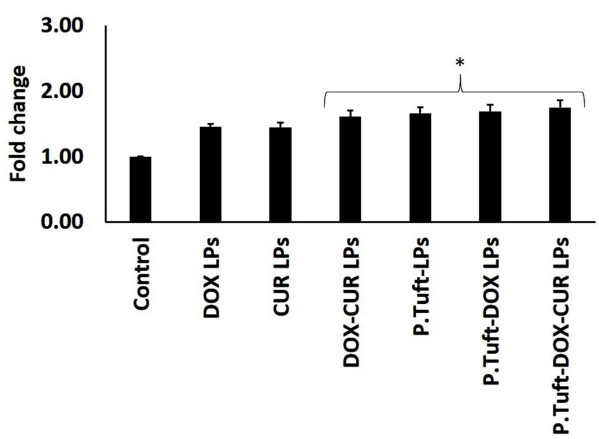

Figure 8 Apoptosis protein expression in tumor tissues.

Notes: Western blot analysis and quantification of Apoptosis-related proteins (A). The cell lysates were subjected to SDS-PAGE and blotted with Bax (B), p53 (C) and BCL-2 (D) antibodies. The data are representative of three experiments. Each value represents mean $\pm S D$ of three experiments. (Figure 9$) * P<0.05$, $* * P<0.0$ I.

pigmentation; new blood vessel formation (angiogenesis) and changes in sinuses and lymphoid follicles. The histopathological changes in liver and tumor tissue of the treatment groups indicated a significant reduction in hyperplasia and angiogenesis in comparison with the controls (Figure 11). The results indicate that there was a significant improvement in the pathological condition of the tumor and organs after treatment with P.Tuft-CUR LPs, P.Tuft-DOX LPs, P.Tuft-DOX-CUR LPs compared to the controls.

\section{Discussion}

Doxorubicin is a widely used broad-spectrum anti-cancer agent for the treatment of various cancer types. Nevertheless, the use of doxorubicin is associated with several setbacks, primarily induction of multi drug resistant (MDR) gene expression owing to internalisation of the drug in cytoplasmic vesicles. ${ }^{22}$ The reasons for drug resistance may be due to the activation of drug-efflux pump which removes the drug from the cells leading to a low concentration of intracellular drug levels. Furthermore,
MDR has been associated with $\mathrm{ABC}$ transporter proteins such as MRP-1 (multidrug resistance associated protein) and Pgp (P-glycoprotein). ${ }^{16}$ To this end, curcumin has been found to downregulate $\mathrm{ABC}$ transporters including MRP-1, P-gp and ABCC1 that are linked to MDR. ${ }^{23,24}$ Earlier studies have shown that nanoformulations of curcumin in combination with doxorubicin could overcome MDR in tumor cells. For instance, Duan et al ${ }^{17}$ demonstrated that loading of both DOX and CUR in chitosan/ poly(butylcyanoacrylate) nanoparticles reversed the multidrug resistance in $\mathrm{MCF}-7$ breast cancer cell lines; NanoDOXCur (NDC) a composite polymer nanoformulation have shown to reduce DOX related cardiomyopathy; ${ }^{25}$ co-encapsulation of DOX and CUR in poly(D,L-LactideCo-Glycolide) nanoparticles suppressed the progression of MDR in leukaemia cell line $\mathrm{K} 562 .^{22}$ In order to take advantage of these pleiotropic properties of curcumin, our study aimed to develop curcumin doxorubicin coloaded liposomal system. Furthermore, in this study liposomes were used as nanocarriers, owing to its enhanced 


\section{P53 tumor suppressor protein}

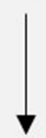

P53 activation

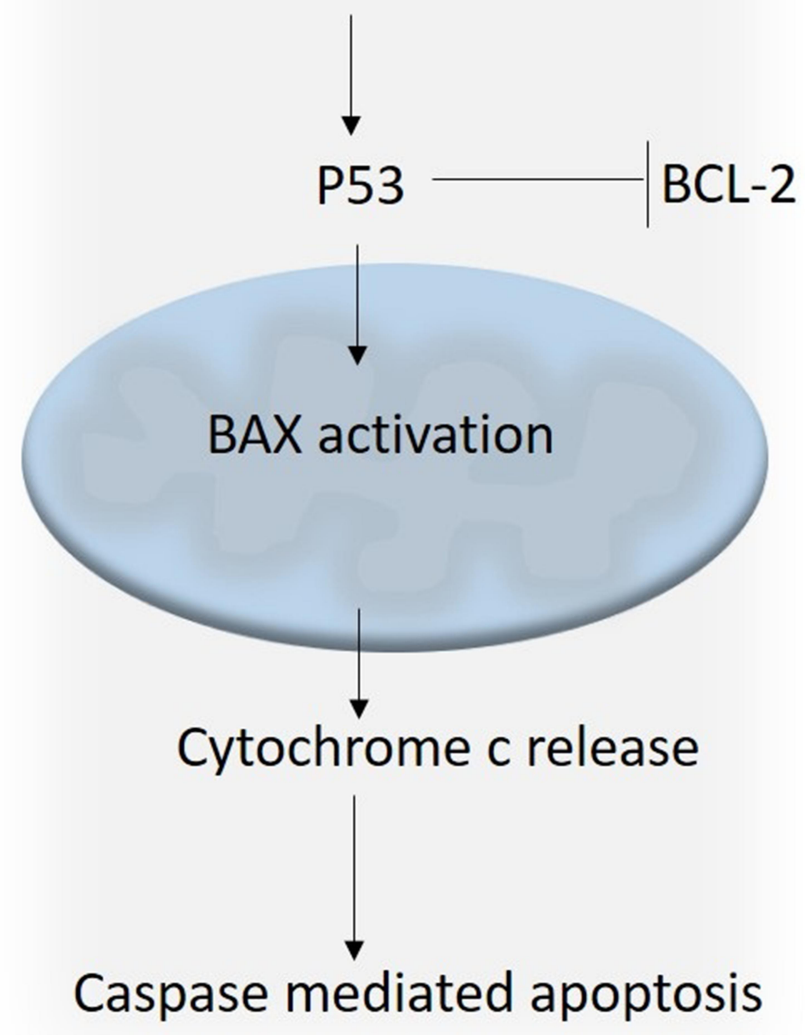

Figure 9 Schematic representation of $\mathrm{p} 53$-mediated apoptotic pathway. Abbreviations: Bax, Bcl-2 Associated X-protein; BCL-2, B-cell lymphoma 2; 553 , tumor protein $\mathrm{p} 53$.

stability, bioavailability, and shelf life for sensitive ingredients as they are assembled from phospholipid bilayers similar to cell membranes and their biphasic character making them suitable for being carriers for both hydrophilic (in the central aqueous compartment) and hydrophobic (in lipid bilayers) compound. ${ }^{26,27}$

Tuftsin a tetrapeptide (Thr-Lys-Pro-Arg) stimulates immunomodulatory effects by binding specifically to macrophages, monocytes, and polymorphonuclear leukocytes $(\mathrm{PMN}){ }^{28}$ Many studies have reported the anti-tumor efficacy of tuftsin in animal models. ${ }^{29,30}$ The intrinsic anticancer/antitumor property of tuftsin makes it an ideal candidate to be administered along with potent anticancer drugs in order to efficiently treat various types of cancers. In the present study, we evaluated the anti-tumor activity of palmitoyl tuftsin-grafted liposomes co-encapsulated with dual/single drug.

It has been demonstrated that the liposomes encapsulated with both CUR and DOX along with P.Tuft effectively inhibited the tumor growth (P.Tuft-CUR LPs, P.Tuft-DOX LPs, P.Tuft-DOX-CUR LPs, $\mathrm{P}<0.01$ ) in experimental animals, compared with the liposomes loaded with either drug alone/peptide alone (CUR LPs, DOX LPs, DOX-CUR LPs, P.Tuft LPs, $\mathrm{P}<0.05$ ), suggesting synergy between the antitumor efficacies of P.Tuft and combination of doxorubicin with curcumin (Figure 7). This may be attributed to efficient uptake of P.Tuft-bearing drug-loaded liposomes by the tumor tissue and then modulation of $\mathrm{ABC}$ drug transporters function by curcumin. This is in accordance with an earlier study which showed that tuftsin-bearing liposomized etoposide, significantly inhibited the tumor growth at a dosage of $10 \mathrm{mg} / \mathrm{kg}$ when administered for five days. ${ }^{8}$ Based on these findings, we hypothesize that doxorubicin from the liposomes efficiently reaches the tumor vasculature with the help of curcumin and exerts its cytotoxicity. In addition, the anti-tumor activity of tuftsin perhaps is manifested through the stimulation of cytotoxic effector cells, such as PMN, macrophages, and natural killer cells, rather than by direct cytotoxicity. This finds support from studies of Florentin et $\mathrm{al}^{31}$, which demonstrated that mice treated with tuftsin showed tumor-specific cytostatic activity through activated peritoneal macrophages, and also enhanced antibodydependent cellular cytotoxicity (ADCC).

Tumor cells are known to have dysregulated apoptotic machinery; therefore, several anti-tumor drugs/therapies aim at regulating the disturbed apoptotic machinery. ${ }^{32,33}$ BAX a pro-apoptotic regulator belonging to the BCL-2 protein family plays a key role in induction of apoptosis in tumor cells. ${ }^{34}$ p53 a tumor suppressor protein can intervene at crucial steps of apoptosis by localisation to mitochondria. ${ }^{35}$ Once translocated to nucleus p53 interacts with BCL-2 and neutralises it thereby altering the ratio of BAX to BCL-2. ${ }^{36}$ Any drug/peptide that activates BAX signify anticancer treatment by regulation of apoptosis. ${ }^{37}$ In the present study, we have found induction in the expression of p53 $(\mathrm{P}<0.05)$ and $\mathrm{BAX}(\mathrm{P}<0.01)$ significantly in P.Tuftsin treatment groups in comparison to control groups. Whereas the expression of BCL-2 $(\mathrm{P}<0.05)$ was significantly downregulated in P.Tuftsin treatment groups (Figure 8). The mechanism involves upregulation of BAX via p53-mediated apoptosis. The results find support from the earlier studies, wherein omega- 3 conjugatebearing tuftsin tagged liposomes delayed progression of 

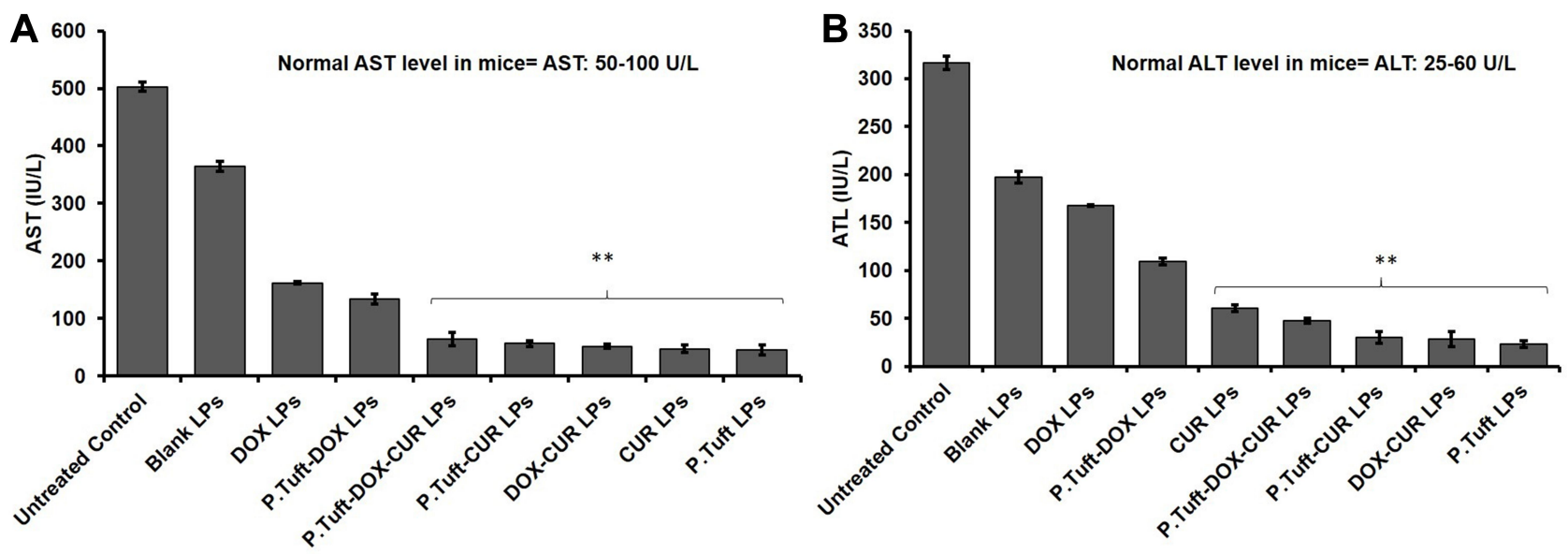

Figure 10 Assessment of liver toxicity in mice on treatment with different kinds of LPs.

Notes: Quantification of plasma concentration of AST (A) and ALT (B) after 30 days of treatment with different kinds of LPs. Each value represents mean \pm SD of three experiments. $* * \mathrm{P}<0.0 \mathrm{I}$, compared with the untreated control.

Abbreviations: AST, aspartate aminotransferase; ALT, alanine aminotransferase.

Tumor
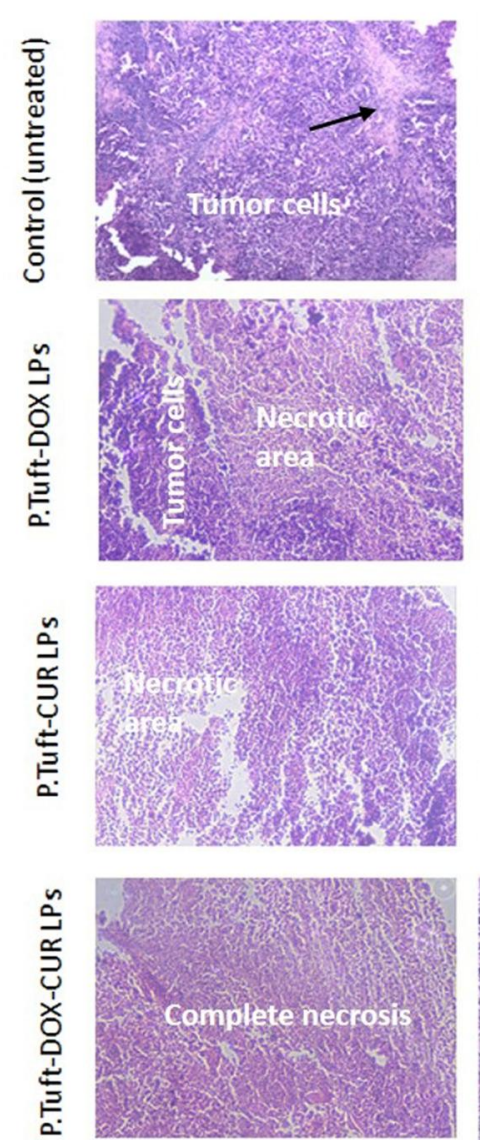

Spleen
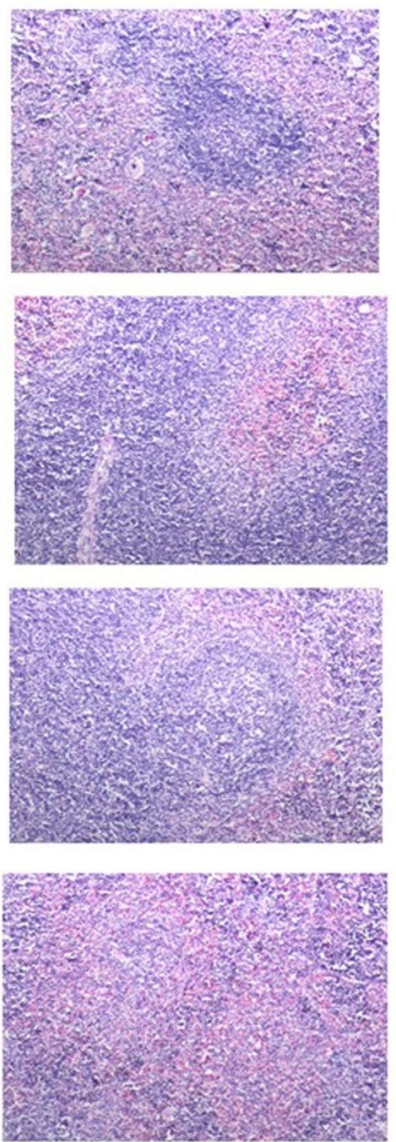

Liver
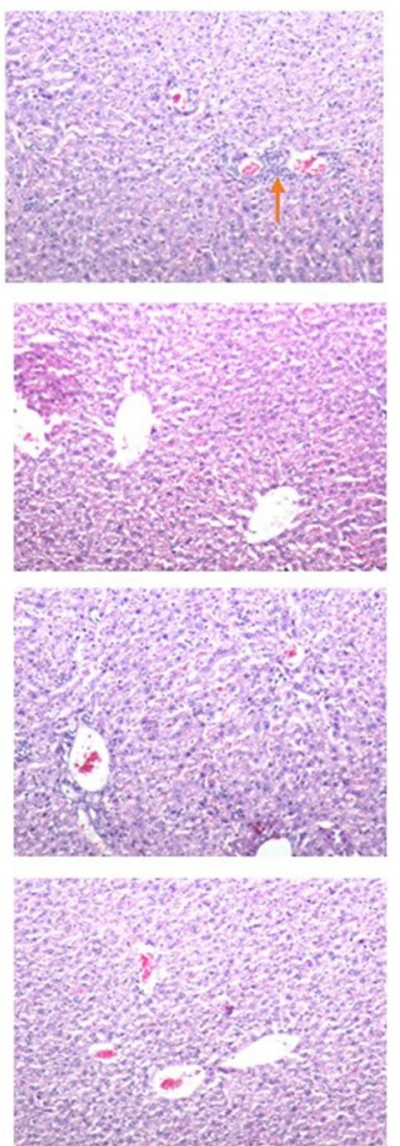

Kidney
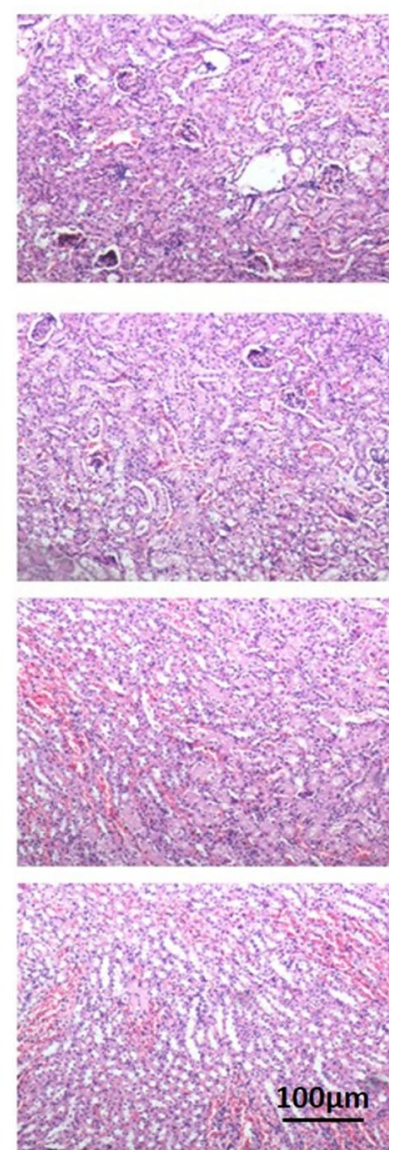

Figure II The micrographs of H\&E-stained sections of the main organs and tumors after treatment with different kinds of LPs.

Notes: Hematoxylin and eosin-stained tumor, liver, spleen and kidney tissue after treatment of mice (treatment every second day for 30 days). Angiogenesis (black arrow), hyperplasia (red arrow). The images were observed at $20 \times$ magnification. 
hepatocarcinoma by regulation of BAX/BCL2 expression in animal model. ${ }^{38}$ Another study with tuftsin-bearing liposomized etoposide (Tuft-Lip-ETP) delayed tumor growth in Swiss albino mice with fibrosarcoma by upregulation of $\mathrm{p} 53 .{ }^{8}$ It could be confirmed that the selective tumor suppression in the tuftsin treatment groups may be due to the induction of p53-mediated apoptosis.

The biochemical analyses (Figure 9) revealed that various liposomal formulations showed no significant toxicity at the administered dose $(10 \mathrm{mg} / \mathrm{Kg})$. This is in accordance with earlier studies, wherein mice showed no visible toxicity upon injecting in them up to $400 \mathrm{mg}$ of tuftsin per $\mathrm{kg}$ of body weight. ${ }^{39}$ Besides, DOX LPs and P.Tuft-DOX LPs showed slightly elevated levels of ALT/AST but the toxicity level of doxorubicin was suppressed in combination with curcumin. In agreement with this study, it has been shown that curcumin effectively reversed the toxicity of doxorubicin by down regulation of P-gp and blocking its transport function in breast cancer cell line. ${ }^{17}$ Another study on leukemia cell line indicated that curcumin reduced the toxic side effect of doxorubicin by down regulation of MDR transporters and inhibition of nuclear factor kappa B (NFkB). ${ }^{22}$

In conclusion, the results of the study suggest that the synthesised liposomes (P.Tuft-CUR LPs, P.Tuft-DOX LPs, P.Tuft-DOX-CUR LPs) are potent anti-tumorigenic formulations against solid tumors. We believe that with further optimisation of the dosage and ratio of the drugs/peptide the combination therapy could be used for less toxic and more effective cancer treatments.

\section{Acknowledgments}

This research was funded by DBT BioCare women scientist scheme. The authors want to thank the Institute of Bioinformatics and Applied Biotechnology (IBAB) for providing the animal house facility.

\section{Disclosure}

The authors report no conflicts of interest for this work.

\section{References}

1. Glasgow MDK, Chougule. MB. Recent developments in active tumor targeted multifunctional nanoparticles for combination chemotherapy in cancer treatment and imaging. J Biomed Nanotechnol. 2015;11 (11):1859-1898. doi:10.1166/jbn.2015.2145

2. Pastorino F, Brignole C, Paolo DD, et al. Targeting liposomal chemotherapy via both tumor cell-specific and tumor vasculature-specific ligands potentiates therapeutic efficacy. Cancer Res. 2006;66(20):10073-10082. doi:10.1158/0008-5472.CAN-06-2117
3. Barui S, Saha S, Mondal G, Haseena S, Chaudhuri A. Simultaneous Delivery of doxorubicin and curcumin encapsulated in liposomes of pegylated RGDK-lipopeptide to tumor vasculature. Biomaterials. 2014;35(5):1643-1656. doi:10.1016/j.biomaterials.2013.10.074

4. Sengupta S, Eavarone D, Capila I, et al. Temporal targeting of tumour cells and neovasculature with a nanoscale delivery system. Nature. 2005;436(7050):568-572. doi:10.1038/nature03794

5. Agarwal A, Kandpal H, Gupta HP, Singh NB, Gupta CM. Tuftsinbearing liposomes as rifampin vehicles in treatment of tuberculosis in mice. Antimicrob Agents Chemother. 1994;38(3):588-593.

6. Owais M, Ahmed I, Krishnakumar B, Jain RK, Bachhawat BK, Gupta CM. Tuftsin-bearing liposomes as drug vehicles in the treatment of experimental aspergillosis. FEBS Lett. 1993;326(1-3):56-58. doi:10.1016/0014-5793(93)81760-W

7. Agrawal AK, Gupta CM. Tuftsin-bearing liposomes in treatment of macrophage-based infections. Adv Drug Deliv Rev. 2000;41 (2):135-146. doi:10.1016/S0169-409X(99)00061-7

8. Khan A, Khan AA, Varun Dwivedi MG, Ahmad SH, Owais M. Tuftsin augments antitumor efficacy of liposomized etoposide against fibrosarcoma in Swiss Albino Mice. Mol Med. 2007;13(5-6):266-276. doi:10.2119/2007-00018.Khan

9. Zou B, Xia S, Xiaohui D, et al. Treatment effect of tuftsin and antigen peptide combined with immune cells on colorectal cancer. Med Sci Monit. 2019;25:5465-5472.

10. Nissen JC, Selwood DL, Tsirka SE. Tuftsin signals through its receptor neuropilin-1 via the transforming growth factor beta pathway. J Neurochem. 2013;127(3):394-402. doi:10.1111/jnc.12404

11. Siebert A, Gensicka-Kowalewska M, Cholewinski G, Dzierzbicka K. Tuftsin - properties and analogs. Curr Med Chem. 2017;24 (34):3711-3727. doi:10.2174/0929867324666170725140826

12. Mohammad N, Singh SV, Malvi P, et al. Strategy to enhance efficacy of doxorubicin in solid tumor cells by methyl- $\beta$-cyclodextrin: involvement of p53 and fas receptor ligand complex. Sci Rep. 2015;5 (1):11853. doi:10.1038/srep11853

13. Pugazhendhi A, Edison TN, Velmurugan BK, Jacob JA, Karuppusamy I. Toxicity of Doxorubicin (Dox) to different experimental organ systems. Life Sci. 2018;200(May):26-30. doi:10.1016/j. lfs.2018.03.023

14. Zhang Q, Wei D, Liu J. In vivo reversal of doxorubicin resistance by (-)-epigallocatechin gallate in a solid human carcinoma xenograft. Cancer Lett. 2004;208(2):179-186.

15. Yu LL, Wu JG, Dai N, Yu HG, Si JM. Curcumin reverses chemoresistance of human gastric cancer cells by downregulating the NF- $\mathrm{kB}$ transcription factor. Oncol Rep. 2011;26(5):1197-1203.

16. Ganta S, Amiji M. Coadministration of paclitaxel and curcumin in nanoemulsion formulations to overcome multidrug resistance in tumor cells. Mol Pharm. 2009;6(3):928-939. doi:10.1021/mp800240j

17. Duan J, Mansour HM, Zhang Y, et al. Reversion of multidrug resistance by co-encapsulation of doxorubicin and curcumin in chitosan/poly(butyl cyanoacrylate) nanoparticles. Int J Pharm. 2012;426 (1-2):193-201. doi:10.1016/j.ijpharm.2012.01.020

18. Sercombe L, Veerati T, Moheimani F, Wu SY, Sood AK, Hua S. Advances and challenges of liposome assisted drug delivery. Front Pharmacol. 2015;6(December):286. doi:10.3389/fphar.2015.00286

19. Gupta CM, Haq W. Tuftsin-bearing liposomes as antibiotic carriers in treatment of macrophage infections. Methods Enzymol. 2005;391:291-304.

20. Jiang T, Zhang Z, Zhang Y, et al. Dual-functional liposomes based on pH-responsive cell-penetrating peptide and hyaluronic acid for tumor-targeted anticancer drug delivery. Biomaterials. 2012;33 (36):9246-9258. doi:10.1016/j.biomaterials.2012.09.027

21. Murugesan K, Koroth J, Srinivasan PP, et al. Effects of green synthesised silver nanoparticles (ST06-AgNPs) using curcumin derivative (ST06) on human cervical cancer cells (HeLa) in vitro and EAC tumor bearing mice models. Int J Nanomed. 2019;14:5257-5270. doi:10.2147/IJN.S202404 
22. Misra R, Sahoo SK. Coformulation of doxorubicin and curcumin in poly(D,L-lactide-co-glycolide) nanoparticles suppresses the development of multidrug resistance in K562 cells. Mol Pharm. 2011;8 (3):852-866. doi:10.1021/mp100455h

23. Limtrakul P, Chearwae W, Shukla S, Phisalphong C, Ambudkar SV. Modulation of function of three $\mathrm{ABC}$ drug transporters, P-glycoprotein (ABCB1), mitoxantrone resistance protein (ABCG2) and multidrug resistance protein 1 (ABCC1) by tetrahydrocurcumin, a major metabolite of curcumin. Mol Cell Biochem. 2007;296(1-2):85-95. doi:10.1007/s11010-006-9302-8

24. Chearwae W, Chung-Pu W, Chu H-Y, Randall Lee T, Ambudkar SV, Limtrakul P. Curcuminoids purified from turmeric powder modulate the function of human multidrug resistance protein 1 (ABCC1). Cancer Chemother Pharmacol. 2006;57(3):376-388.

25. Pramanik D, Campbell NR, Das S, et al. A composite polymer nanoparticle overcomes multidrug resistance and ameliorates doxorubicin-associated cardiomyopathy. Oncotarget. 2012;3 (6):640-650. doi:10.18632/oncotarget.543

26. Bulboacă AE, Boarescu PM, Bolboacă SD, et al. Comparative effect of curcumin versus liposomal curcumin on systemic pro-inflammatory cytokines profile, MCP-1 and RANTES in experimental diabetes mellitus. Int J Nano. 2019;14:8961-8972.

27. Bulboaca AE, Boarescu P-M, Porfire AS, et al. The effect of nano-epigallocatechin-gallate on oxidative stress and matrix metalloproteinases in experimental diabetes mellitus. Antioxidants (Basel, Switzerland). 2020;9:2.

28. Nishioka K, Amoscato AA, Babcock GF. Tuftsin: a hormone-like tetrapeptide with antimicrobial and antitumor activities. Life Sci. 1981;28(10):1081-1090. doi:10.1016/0024-3205(81)90684-6

29. Nishioka K, Babcock GF, Phillips JH, Banks RA, Amoscato AA. In vivo and in vitro antitumor activities of tuftsin. Ann N Y Acad Sci. 1983;419(1 Antineoplasti):234-241. doi:10.1111/j.1749-6632.1983. tb37109.x
30. Nishioka K, Babcock GF, Phillips JH, Noyes RD. Antitumor effect of tuftsin. Mol Cell Biochem. 1981;41(December):13-18. doi:10.1007/ BF00225293

31. Florentin I, Bruley-Rosset M, Kiger N, et al. In vivo immunostimulation by tuftsin. Cancer Immunol Immunother. 1978;5(3):211-216. doi:10.1007/BF00199631

32. Zhivotovsky B, Orrenius S. Defects in the apoptotic machinery of cancer cells: role in drug resistance. Semin Cancer Biol. 2003;13 (2):125-134. doi:10.1016/S1044-579X(02)00130-X

33. Reed JC. Apoptosis-regulating proteins as targets for drug discovery. Trends Mol Med. 2001;7(7):314-319. doi:10.1016/S1471-4914(01) 02026-3

34. Brady HJM, Gil-Gómez G. Molecules in focus bax. The pro-apoptotic Bcl-2 family member, bax. Int J Biochem Cell Biol. 1998;30(6):647-650. doi:10.1016/S1357-2725(98)00006-5

35. Ryan KM, Phillips AC, Vousden KH. Regulation and function of the p53 tumor suppressor protein. Curr Opin Cell Biol. 2001;13 (3):332-337. doi:10.1016/S0955-0674(00)00216-7

36. Basu A, Haldar S. The relationship between BcI2, bax and p53: consequences for cell cycle progression and cell death. Mol Hum Reprod. 1998;4(12):1099-1109. doi:10.1093/molehr/4.12.1099

37. Schendel SL. Characterization of BC1-2, BC1-XL, and bax pore formation and their role in apoptosis regulation. 1999. doi:10. 21236/ada383308

38. Khan AA, Alanazi AM, Jabeen M, Hassan I, Bhat MA. Targeted nano-delivery of novel omega-3 conjugate against hepatocellular carcinoma: regulating COX-2/bcl-2 expression in an animal model. Biomed Pharmacother. 2016;81(July):394-401. doi:10.1016/j.biopha. 2016.04.033

39. Khan MA, Owais M. Toxicity, stability and pharmacokinetics of amphotericin $\mathrm{b}$ in immunomodulator tuftsin-bearing liposomes in a murine model. J Antimicrob Chemother. 2006;58(1):125-132. doi:10.1093/jac/dk1177
International Journal of Nanomedicine

\section{Publish your work in this journal}

The International Journal of Nanomedicine is an international, peerreviewed journal focusing on the application of nanotechnology in diagnostics, therapeutics, and drug delivery systems throughout the biomedical field. This journal is indexed on PubMed Central, MedLine, CAS, SciSearch ${ }^{\circledR}$, Current Contents ${ }^{\circledR} /$ Clinical Medicine,

\section{Dovepress}

Journal Citation Reports/Science Edition, EMBase, Scopus and the Elsevier Bibliographic databases. The manuscript management system is completely online and includes a very quick and fair peer-review system, which is all easy to use. Visit http://www.dovepress.com/ testimonials.php to read real quotes from published authors. 